\title{
La inmunología política masculina. El "populismo de derechas" y la fobia a la penetración
}

\author{
The Masculine Political Immunology. "Right-Wing Populism" and \\ the penetration phobia
}

ALBERTO CORONEL TARANCÓN*

\begin{abstract}
Resumen: el artículo aborda el debate en torno del «populismo de derechas» desde un enfoque biopolítico, analizando los fenómenos vinculados al populismo de derecha como signos que evidencian la existencia de inmunología política masculina, desplazando el acento analítico del racismo xenófobo a la fobia a la penetración y del populismo a la política masculina.

Palabras clave: populismo de derechas, masculinidad política, inmunología política, Michel Foucault, Pierre Bourdieu, Wendy Brown.
\end{abstract}

\begin{abstract}
: this article approaches the debate on "Right-Wing Populism" from a biopolitical standpoint, analyzing the social phenomena linked to "Right-Wing Populism" as pointing to the existence of a masculine political immunology, displacing the analytical emphasis from racist xenophobia to penetration phobia and from populism to manhood politics.

Key words: Right-Wing Populism, manhood politics, political immunology, Michel Foucault, Pierre Bourdieu, Wendy Brown.
\end{abstract}

\section{Introducción}

La cadena argumental que vertebra este artículo distingue cinco partes. Primero, mostramos la centralidad el factor antiinmigración en el espectro de los llamados "populismos de derechas", y nos preguntamos qué factores intervienen en la codificación de la anomalía migratoria en una anomalía patológica (2). Para ello, en segundo lugar, sugerimos la necesidad de pensar lo intersección entre lo biológico y lo político a partir de Michel Foucault y George Canguilhem, de la que extraemos cuatro principios básicos de una comprensión

Recibido: 06/07/2017. Aceptado: 19/02/2018.

* Alberto Coronel Tarancón es investigador predoctoral y docente en formación con un contrato de Formación de Profesorado Universitario en la Facultad de Filosofía de la Universidad Complutense de Madrid. Esta investigación ha sido llevada a cabo en el marco del proyecto de investigación "Biblioteca Saavedra Fajardo (V): populismo vs. Republicanismo. El reto político de la segunda globalización” (FFI2016-75978-R) dirigida por José Luis Villacañas Berlanga y financiado por el Ministerio de Ciencia e Innovación. En la actualidad, su actividad investigadora se concentra en el análisis de las relaciones entre populismo y neoliberalismo en el marco de la biopolítica y los estudios sobre gubernamentalidad. También es autor de "La «gubernamentalidad metabólica» en disputa. Apuntes sobre neoliberalismo y metabolismo social” (2018), Res publica, 21.3, pp. 571-583. Correo electrónico: acoronel@ucm.es. 
de la inmunología política alternativa a la propuesta por Roberto Esposito (3). En el espacio abierto entre la ontología vitalista de Canguilhem y la ontología histórica de Foucault, el concepto de habitus de Pierre Bourdieu nos permite identificar la masculinidad con el conjunto de estructuras y disposiciones prácticas que evalúan lo viril como valioso y lo feminizante como patológico (4). A partir de ese modelo, exponemos, siguiendo los pasos de Wendy Brown, la hipótesis central de este trabajo: la presencia de una inmunología política masculina y la fobia a la penetración como condición necesaria y no suficiente tras los "populismos de derechas" y el auge electoral de los partidos y discursos antiinmigración (5).

\section{Una constante difusa: populismos de derechas y el rechazo a la inmigración}

En diciembre de 2016 Boris Pdobnik, Marko Jusup y Eugene Stanley, vinculados a la Universidad de Boston, Rijeka (Croacia), a la universidad de Hokkaido (Japón) y de Luxemburgo, publicaron un estudio estadístico titulado "Predicting the rise of right-wing populism in response to unbalanced immigration" , donde unbalanced hace referencia a los diferenciales entre frecuencia de entrada de inmigrantes y las frecuencias de la integración socioeconómica. Los autores comparan datos de Alemania, Austria, Francia, Dinamarca, Bélgica, Polonia, Suecia, Finlandia, Noruega, Ucrania, Italia y Grecia, y se preguntan, primero, si es posible predecir en qué circunstancias el populismo de derechas puede obtener el suficiente apoyo para producir cambios políticos y económicos drásticos, y segundo, si es predecible, tomando los efectos de la globalización como constante, un efecto dominó o reacción en cadena que reproduzca por contagio el populismo de derechas de varios países.

El estudio responde afirmativamente a ambas preguntas: existe una evidente correlación entre, por un lado, la prevalencia de inmigrantes en un país y periodo, el total de inmigrantes que entran en la unidad político-territorial y el incremento del apoyo al "populismo" de derechas en esa geografía política (como sería la Europa del Schengen). A su vez, muestran que la subida del apoyo electoral en un país no tiene por qué coincidir con la llegada de inmigrantes a ese mismo territorio, lo que desemboca en la conclusión de que el efecto cadena es altamente probable: "nadie quiere ser el primero, pero muchos esperan ser los segundos"2. De mantenerse la tendencia el «RW populism» acabaría por imponerse y, con el tiempo, producir un movimiento recesivo en la globalización (entendida aquí como proceso vinculado al libre tráfico de personas y mercancías a través de los territorios nacionales). Entender este "cambio de corazón" - la adhesión de la población a la intolerancia - , dicen los estadistas económicos, es de máxima importancia para el éxito de la globalización ${ }^{3}$.

A partir de aquí, planteamos las siguientes preguntas: si los efectos políticos de la inmigración no se agotan allí donde hay un contacto directo con los flujos migratorios, sino que se extienden por contagio a las poblaciones que no han entrado en contacto con los mismos, ¿qué información es la que se transmite de una población a otra?, ¿qué mecanismos operan para que esa anomalía - cierto tipo y volumen de inmigración - sea interpretada como una amenaza? ¿Es la xenofobia?, ¿la aporofobia?, ¿la misoginia?, ¿la economía?, ¿la ideología

1 Podobnik, Boris; Jusup, Marko; Stanley, H. Eugene, "Predicting the rise of right-wing populism in response to unbalanced immigration", arXiv, 2016

2 Ibid.p. 9

3 Ibid. p. 1 
de sus líderes?, ¿el estilo discursivo catch-all de los políticos?, ¿la construcción de un «we the people» contra un Otro que lo amenaza? En una comparativa del Frente Nacional Francés, el belga Vlaams lok, el Duch Centrumpartij holandés, el Partido Austriaco por la Libertad (FPÖ), e Danish Fremskridtspartiet o el German Republikaner Party, entre otros, Meindert Fennemz llega a la siguiente conclusión: pese a la aparente centralidad de sentimientos anti-establishment (rasgo compartido con los partidos de extrema izquierda), "the only pragmmatic issue all radical right parties have in common is their resentment against immigrants and against the immigration policies of their government. To call these parties extreme right is therefore misleading. We will call them anti-inmigrant parties instead"4.

Elisabeth Ivarsflaten se muestra escéptica con la centralidad de la fobia a la inmigración como locus universal del populismo de derechas, y argumenta que tras su éxito electoral se distribuyen de manera variable los efectos de la economía, y los sentimientos antistablishment ${ }^{5}$. Jens Rydgren reconoce la centralidad del factor antiinmigración y distingue entre actitudes xenófobas y escépticas, argumentando que no todo rechazo político a la inmigración o las políticas migratorias implica, necesariamente, una actitud xenófoba ${ }^{6}$, lo que por otra parte ha sido corroborado en las situaciones en que la llegada de mano de obra inmigrante transforma las condiciones laborales locales. En el marco de este debate, la victoria de Donald Trump y la centralidad en su programa político de su great wall; la centralidad de la importancia de los inmigrantes en el Brexit y los altercados xenófobos, islamófobos y homófobos que acompañaron a los días siguientes de las elecciones, nos puso en la pista de una hipótesis que la politóloga y filósofa norteamericana Wendy Brown ya había perfilado en su obra Walled States, Waning Sovereignty (2010) ${ }^{7}$. Brown muestra que las demandas masivas de fronteras, muros y barreras físicas tienen un fuerte componente identitario y libidinal que debemos interrogar en las profundidades del vínculo que une la identidad política y las líneas fronterizas. Otro de los factores señalados por Brown en sus investigaciones es que los mismos flujos migratorios que una mañana son mano de obra desposeída, fácilmente explotable y privada, por la tarde aparecen metamorfoseados como amenaza capaz de socavar las bases económicas, culturales y axiológicas de las sociedades occidentales.

Nuestro objetivo es mostrar que el logos oculto de estas mutaciones está directamente vinculado con la masculinidad operativa en las sociedades patriarcales. Por patriarcado entendemos lo que Gerda Lerner: "la manifestación e institucionalización del dominio masculino sobre las mujeres y niños/as de la familia y la ampliación de ese dominio sobre las mujeres en la sociedad en general""; por masculinidad, lo que Pierre Bourdieu: el conjunto

4 Meindert, Fennemz, "Populist Parties of the Right" en Movements of Exclusion: Radical Right-Wing Populism in the Western World.. Ed. Jens Rydgren. Nova Science Publishers. New York, 2005, p.1

5 Ivarsflaten, Elisabeth, "What Unites Right-Wing Populists?", Comparative Political Studies, Vol. 41, 2008, pp. $3-23$

6 Rydgren, Jens, “Inmigration sceptics, xenophobes or racists?”, European Journal of Political Research, Vol. 47, 2008, pp. 737-765

7 Brown, Wendy, Estados amurallados, soberanía en declive, Barcelona, Herder Editorial, 2015

8 Lerner, Gerda, La creación del patriarcado. Crítica, Barcelona, 1990, pp. 340-341. Al igual que Kate Millet, Lerner sitúa la dominación de género como anticipo formal de todas las dominaciones estructurales y simbólicamente naturalizadas: "De esta manera la esclavitud de las mujeres, que combina racismo y sexismo a la vez, precedió a la formación y a la opresión de clases. Las diferencias de clases estaban en sus comienzos expresadas 
de disposiciones y esquemas cognitivos de apreciación y valoración implícitos en la praxis cotidiana de los agentes sociales que constituyen los elementos objetivamente subjetivos del patriarcado como sistema de dominación ${ }^{9}$. La masculinidad sería así la encargada de codificar las novedades como simples anomalías o como portadoras de un peligro o riesgo para el statu quo del orden social en que se esos mismos códigos sociales están normalizados. La norma actúa como un sensor político producido históricamente e incorporado que se activa ante las señales (reales, simbólicas o imaginarias) que éste mismo sensor codifica como amenazas.

Si observamos el primer estudio citado ${ }^{10}$, tras el «populismo de derechas» no habría más que índices de intolerancia cuantificables (votos a partidos de extrema derecha, agresiones, manifestaciones, discursos), pero ¿qué mecanismos subyacen a esa intolerancia? El mismo estudio señala que la percepción de inmigraciones anómalas como patológicas se produce sin que exista necesariamente un contacto directo con la población migrante ${ }^{11}$, luego, si los fenómenos sociales resultan inexplicables como inmediatez del contacto, ¿qué elementos median en la percepción de la inmigración anómala como una amenaza?

\section{Lo normal, lo patológico y la inmunología política de las poblaciones}

Denominamos anormal al modo en que la diferencia comparece a la luz de la normalidad, y sabemos que lo patológico no es la figura inversa de la norma, luego, ¿cuándo se nos presenta lo anormal como patológico? En la extensa genealogía de las instituciones modernas elaborada por Michel Foucault en la década de los setenta, la diferencia normal-patológico constituye un factor epistemológico capital en la captura histórica de la vida por las mallas del poder político. En su analítica del biopoder, los factores epistemológicos que indican la entrada de la vida en lo político son cuatro: función, organismo, medio y población. "Éstos definen una 'regularidad en la dispersión' de los enunciados científicos sobre la vida en la modernidad, constituyen el suelo a partir del cual es pensable modernamente la Vida"12. En correspondencia con estos índices de modernidad biológica encontramos los dispositivos del biopoder que permitieron i) la transformación de las masas en cuerpos dóciles y funcionales (dispositivo de seguridad ${ }^{13}$ ), ii) la producción de una sexualidad que sirviera para impregnar de biología los códigos de reconocimiento e interacción entre organismos sexualmente diferenciados (dispositivo de sexualidad ${ }^{14}$ ), iii) la producción de un medio urbano que organizase la circulación regulada de los flujos organismos, mercancías y residuos, maximizando los efectos positivos y reduciendo al mínimo los efectos patológicos de la acumulación de organismos humanos (dispositivos de seguridad ${ }^{15}$ ). Estos flujos, iv) dibujarán, ante los ojos

y constituidas en función de las relaciones patriarcales. La clase no es una construcción aparte del género, sino que más bien la clase se expresa en términos de género". Lerner, Gerda, Ibid. p, 311

9 Bourdieu, Pierre, La dominación masculina. Barcelona, Anagrama, 2015

10 Podobnik, B., et Al.., "Predicting the rise of right-wing populism in response to unbalanced immigration", $O p$. Cit., p.4

11 Ibid.p. 2

12 Sacchi, E., "Umbrales biológicos de la modernidad política en Michel Foucault", Daimon. Revista Internacional de Filosofía, 2016, núm. 68, p. 20

13 Foucault, M., Vigilar y castigar: Nacimiento de la prisión. Madrid, Biblioteca Nueva, 2012

14 Foucault, M., Historia de la sexualidad I. La voluntad de saber, México, Siglo XXI, 2009

15 Foucault, M.., Seguridad, territorio, población: Curso del Collège de France (1977-1978). Madrid, Akal, 2008 
estadísticos y económicos del poder político, una suerte de metabolismo natural que integra tanto el vientre como el deseo de estos organismos sexuados, lo que va a obligar al poder gubernamental a reconocerse en el interior de esta misma realidad natural y espontánea en que debe calcular y limitar el quantum de su intervención política (problemática del liberalismo y de los dispositivos para el gobierno de las poblaciones ${ }^{16}$ ). Articulados, reforzados e interconectados entre sí, los dispositivos del biopoder conforman un arco relacional que distingue dos polos, muchos centros y varias bisagras. En palabras de Foucault,

Las disciplinas del cuerpo y las regulaciones de la población constituyen los dos polos alrededor de los cuales se desarrolló la organización del poder sobre la vida. El establecimiento, durante la edad clásica, de esa gran tecnología de doble faz — anatómica y biológica, individualizante y especificante, vuelta hacia las realizaciones del cuerpo y atenta a los procesos de la vida - caracteriza un poder cuya más alta función no es ya matar sino invadir la vida enteramente ${ }^{17}$.

Este nuevo pacto histórico del poder político estatal y gubernamental con el hacer vivir rompe (parcialmente) con la lógica tanatopolítica de su pre-modernidad biológica: a partir del siglo XIX, el poder para matar habrá de hacerlo en el nombre de la protección de la vida ${ }^{18}$. El resultado de la articulación compleja de dispositivos en red ofrece el recorte sociohistórico al que Foucault denominó sociedad de normalización. La norma aparece como clave de bóveda de esta composición de funciones articuladas: "el elemento que va a circular de lo disciplinario a lo regularizador, que va a aplicarse del mismo modo al cuerpo y a la población, que permite a la vez controlar el orden disciplinario del cuerpo y los acontecimientos aleatorios de una multiplicidad biológica [...] es la norma"19.

En este punto estamos obligados a dar un rodeo pues el triángulo formado por los índices de modernidad biológica, la norma y el biopoder en el pensamiento de Foucault nos sitúa ante la bifurcación teórica decisiva para pensar en qué consistiría algo así como una inmunología política diferente de la propuesta por Roberto Esposito. ¿En qué consiste exactamente esta bifurcación? En aceptar o no aceptar la tesis de Esposito por la cual existiría una ambivalencia irresoluble en la noción foucaultiana de biopolítica ${ }^{20}$ que obliga a resolver el enigma biopolítico en el interior de su paradigma inmunitario ${ }^{21}$. Desde esta óptica, el nazismo dejaría de ser el residuo inasumible en el interior de una modernidad biológica nacida para hacer vivir y dejar morir ${ }^{22}$ y se transforma en la figura que mejor la ilustra: una forma comunitaria socialmente organizada en torno a la división democrática del poder de

16 Foucault, M., Nacimiento de la biopolítica: Curso del Collège de France (1978-1979), Madrid, Akal, 2009

17 Foucault, M., Historia de la sexualidad I. La volutad de saber, op. cit, p.169

18 En este punto Foucault hace referencia al racismo como dispositivo que permitió matar legítimamente a quienes significan un peligro biológico: Foucault, M. La historia de la sexualidad I. La voluntad de saber, Op. cit., p. 167; Foucault, M. Hay que defender la sociedad.: Curso del Collège de France (1975-1976), Sevilla, Akal, 2010, pp. 218-221

19 Foucault, M., Hay que defender la sociedad, Op. cit., p. 217

20 Esposito, R., Bíos. Filosofía y biopolítica, Buenos Aires, Amorrortu, 2011, pp. 25; 66-69

21 Ibid.pp. 73-123

22 Ibid. pp. 53-63 
matar para defender la vida ${ }^{23}$. El argumento específico es que biopolítica en Foucault significa simultáneamente ruptura, transformación y conservación respecto del poder soberano, lo que invalida su análisis y nos impediría (como de hecho sucedería en todo el pensamiento biopolítico del siglo $\mathrm{XX}^{24}$ ) operar con una noción de biopolítica solvente.

Consideramos, junto a Adán Salinas ${ }^{25}$, que la contradicción solo es irresoluble en el espacio-conceptual de matriz heideggeriana que le sirve a Esposito de mesa textual de operaciones. Si escapamos de su cuadrícula, rápido identificamos que en la analítica foucaultiana la modernidad biológica carece de la unidad conceptual que le atribuye Esposito. Del sentido metodológico del biopoder en Foucault busca justamente escapar del esquematismo binario al que la crítica de Esposito quiere hacerle retornar. Lo importante no es la ruptura del biopoder con el poder soberano (que Foucault identifica en el fin de los suplicios). Tampoco la continuidad que garantiza y posibilita el racismo como fuente de legitimidad para matar en las sociedades de normalización. La clave reside en las mutaciones inéditas que permiten al biopoder multiplicar y vigorizar sus efectos valiosos, reorganizar y redistribuir sus abundancias y escaseces; localizar y analizar caso a caso sus expresiones endémicas; analizar sus regularidades hasta hacerlas predecibles; disminuir, atenuar, dividir y desplazar sus efectos patológicos. En suma: gobernar todos los propios del ser viviente y humano a través de una orquesta de biopoderes antes desconocidos. Al querer hacer retornar a Foucault al interior de una lógica binaria, y al introducir la comprensión heideggeriana de la comunitas, Esposito no resuelve la biopolítica foucaultiana, sugiere otra ${ }^{26}$.

Por la otra senda de la misma bifurcación, la lectura de Foucault que busca rescatar la influencia de Canguilhem problematiza, antes que una supuesta ambivalencia conceptual, la relación de la noción de vida y dispositivo, en tanto y cuando la primera parece preceder al campo de acciones posibles en que se juega la partida entre la libertad, el poder y la resistencia en el interior de los dispositivos. Al mismo tiempo, Foucault constituiría una suerte de cara B sociocultural respecto de las preocupaciones naturalistas de Canguilhem en el interior del triángulo vida-historia-norma, que, sin coincidir ni estorbarse, comprendería el pensamiento de ambos ${ }^{27}$. Apoyándonos en las principales investigaciones que han trabajado este vínculo, sintetizamos los cuatro principios contenidos en el vínculo Canguilhem-Foucault que hemos considerado más relevantes para nuestros propósitos:

I. La compatibilidad y concordancia de la ontología histórica foucaultiana con la ontología vitalista de Canguilhem: su carácter antiesencialista ha sido caracterizado por Francisco Vázquez García como un vitalismo desfondado, en el cual la integración del viviente con un

23 Ibid. pp. 175-234

24 Ibid. pp. 27-41

25 "Un concepto bio-política, formado por dos palabras bíos y política, queda suficientemente desepajado cuando quedan despejados los conceptos que lo forman, y por el contrario, queda la incertidumbre cuando hereda indecisiones de los conceptos de los que proviene. Puede ser que como criterio general para valorar un concepto el criterio sea adecuado, especialmente si se trata de un concepto heredado de la filosofía antigua. Pero en el caso particular del discurso sobre el biopoder desarrollado por Foucault, simplemente no se ajusta al método" SALINAS, Adán, La semántica biopolítica: Foucault y sus recepciones. Viñas del mar, CENALTES, 2015, p. 269

26 Los principios de la biopolítica de Esposito son analizados de manera sistemática en Sacchi, E. (2015) "Del munus común a la vida impersonal. Comunidad y biopolítica en R. Esposito", Revista Internacional de Comunicación y Desarrollo, 2015, 83-98.

27 Macherey, P. De Canguilhem a Foucault: la fuerza de las normas, Buenos Aires, Amorrortu, 2011, p. 15 
entorno radicalmente cambiante exige que los elementos concretos que participen de su autoconservación creativa (de normas sociales) no pueda ser fijada como norma transhistórica:

Lo que distingue a los individuos vivientes según Canguilhem, es su relación polar con el entorno. La individualidad biológica, desde las bacterias hasta los grandes mamíferos, se configura a partir de una constante preferencia y selección de los estímulos que proceden del entorno. Su inserción en el medio no es pasiva; consiste en un nexo de debate y evaluación permanente, que le lleva a configurar activamente ese medio. Por otro lado, esta polaridad se despliega en un doble movimiento: de supervivencia por autoconservación, manteniendo constante el equilibrio del medio interno en relación con el externo, y de instauración de normas que permiten al viviente variar de entorno..$^{28}$

Esta comprensión del ser vivo concuerda perfectamente con la polaridad poder-resistencia y con la contingencia radical que caracteriza los dispositivos, a la vez que permite armonizar la polaridad del arco del biopoder en las sociedades de normalización con la polaridad normativa del viviente.

II. La afinidad funcional entre la vida y los dispositivos. La vida de las poblaciones humanas no puede dejar de pronunciarse a través de los dispositivos históricos que luchan por el gobierno normado de sus dinámicas. Las normas sociales se integran inmanentemente en "la marcha de los procesos biológicos, dando lugar a un entorno planificado" 29 . Esto ha permitido identificar a Maria Muhle ${ }^{30}$ la armonía tensional existente entre la polaridad del arco del biopoder analizados por Foucault y la polaridad de la vida en Canguilhem: así, mientras que la rigidez del dispositivo disciplinario produce normas para la autoconservación de un orden social - allí donde necesita fijar reglas estables (modelo de la peste ${ }^{31}$ ) - el dispositivo biopolítico regula los flujos de la población permitiendo amplios márgenes de variación que favorecen, flexibilizándolo, la adaptación del conjunto (modelo de la viruela ${ }^{32}$ ).

III. La negación de la comprensión de la enfermedad como desvío cuantitativo respecto de la norma: En Lo normal y lo patológico, "Canguilhem cuestiona el dogma positivista que entiende lo patológico como mera variación cuantitativa respecto a lo normal, pero también pone en tela de juicio la identificación de la enfermedad con la anormalidad, esto es, con la ausencia de normas"33. Esto concuerda a la perfección con la atención prestada por Foucault a la resolución jurídica de la anormalidad. Al mismo tiempo, la no identidad entre el desvío adaptativo y el patológico exige la mediación de dispositivos externos que resuelvan la ambigüedad. Es decir - y este es el rasgo fundamental para nosotros - la codificación

28 Vázquez García, F. “Canguilhem, Foucault y la ontología política del vitalismo”, Logos, vol. 48, 2015, pp. 178.

29 Ibid. p. 186

30 Mühle, M., "Histoire(s) de la vie de Canguilhem á Foucault", en Epistemology and history, from Bachelard and Canguilhem to today's history of science, Berlín, Max Planck Institute for the History of Science, 2012, pp. 187-195

31 Foucault, M., Los anormales, Buenos Aires, Fondo de Cultura Económica, 2014 pp. 39-59; Vázquez García, F., op. cit., p. 186

32 Foucault, M., Seguridad, territorio, población, op. cit., pp. 66-68, apud. Vázquez, Op. cit., p. 186

33 Canguilhem, G.: Le normal et le pathologique, pp. 11-67 apud. Vázquez García, F, Op. cit., p. 179 
de lo anómalo como patológico en relación con el mismo sujeto que contempla la novedad exige desde la necesidad biológica la mediación de dispositivos sociales contingentes.

IV. El isomorfismo entre el biopoder y la bio-resistencia. Al igual que la dimensión físico-mecánica de la corporalidad exige de una microfísica del poder, y la dimensión biológica de las poblaciones demanda dispositivos biopolíticos, toda codificación de una anomalía como patológica exige el isomorfismo entre el poder y la resistencia, la amenaza y la defensa. Esta cuestión es central tanto para la inmunología biológica como para la biopolítica: recordar correctamente (generar el vínculo adecuado entre el pasado y el presente) es la condición de posibilidad de seleccionar las defensas adecuadas generadas por el contacto registrado de una experiencia retenida. Este proceso (biológico y biopolítico) queda siempre abierto a: i) la posibilidad de la escasez de experiencias y recursos: este es el caso de la indefensión o de la inmunodepresión; ii) el error, que puede llevar a identificar un elemento benigno como patológico o confundir una amenaza real con un elemento inocuo: caso de la no-reacción y de las reacciones autoinmunes. En todos los casos la actividad y la reactividad de un determinado código normativo exige que ésta hubiese sido producida, establecida e incorporada por aceptación de las partes o por dictado de la parte en condiciones de producir e imponer normas. Por ende, la dimensión social e histórica de las normas es genealógicamente indiscernible. De aquí que tenga sentido preguntarse, antes que por la biología - ajena a la dimensión sustantiva de las normas que habrán de acompañar sus exigencias - por la dimensión histórica y sociológica de ese código normativo conocido como masculinidad.

\section{La inmunología política masculina: sus normas, sus defensas, sus patologías}

A lo largo y ancho de la historia de Occidente - escribe Wendy Brown al comienzo de su primer libro- "las expectativas, sensibilidades y las actividades cotidianas de la vida humana han estado divididas en dos órdenes generalmente contrapuestos: masculino y femenino" 34 . En el mismo sentido, Evelyne Sullfort - con el propósito de diferenciar los sustratos biológico y político - sostiene que la diferencia hombre-mujer "consideraba a la naturaleza como el origen y la justificación del lugar de las mujeres en la sociedad: tareas, roles, estatutos, poderes, etc. Las referencias a su fisiología presentaban una tal amplitud, y sus representaciones mitológicas e ideológicas una tal autoridad, que disimulaban todos los demás aspectos, más económicos y socioculturales y sus mecanismos de dominación"35. La denuncia de la naturalización de lo cultural y lo político, junto al potencial crítico de la teoría y la praxis intelectual para la desnaturalización de la dominación masculina, son elementos nucleares del pensamiento feminista contemporáneo. Para esta tarea de desnaturalización política, la sociología reflexiva de Pierre Bourdieu se situaría en una posición de mediación entre lo biológico en Canguilhem y lo histórico en Foucault, acentuando la circularidad por la que una norma es creada, andamiada simbólicamente e incorporada por los agentes sociales de tal modo que ésta podrá seguir funcionando sin dejar rastro del momento contingente

\footnotetext{
34 Brown, W., Manhood and Politics: A Feminist Reading in Political Thought. New Jersey, Rowman \& Littlefield, 1988, p.1

35 Sullfort, E., El hecho femenino. Madrid, Argos Vergara, 1979, pp. 18 20.
} 
y político de su imposición. Esta es una de las claves de su estructuralismo genético, según el cual lo psíquico mediado simbólicamente hunde sus raíces en lo social, estableciendo una identidad genética entre los esquemas cognitivos de los agentes sociales (códigos de apreciación y valoración) y las estructuras simbólicas objetivadas en las sociedades ${ }^{36}$. En su monismo relacional de lo social, operan simultáneamente dos dimensiones objetivas: en primer lugar, los recursos escasos que constituyen límites objetivos para los agentes, sus cálculos y expectativas. A esta estructura de elementos que coactan la praxis social las llamará objetividad de primer orden. En segundo lugar, "La teoría más resueltamente objetivista debe integrar la representación que los agentes se hacen del mundo social y, más precisamente, su contribución de la visión de ese mundo y, por lo tanto, a la construcción de ese mundo por medio del trabajo de representación (en todos los sentidos del término) que efectúan sin cesar para imponer su propia visión del mundo o la visión de su propia posición en ese mundo, de su identidad social" ${ }^{37}$. Las estructuras sociales encarnadas, y los efectos prácticos de la lucha por afirmar la propia representación del mundo constituyen la objetividad de segundo orden ${ }^{38}$.

Dentro de este segundo momento objetivamente subjetivo de lo social existen prenociones, «representaciones esquemáticas y sumarias» que se «forman por la práctica y para ella» y que reciben su evidencia y autoridad de las funciones sociales que cumplen ${ }^{39}$. Para identificarlas es necesario "reintroducir la experiencia inmediata y vívida de los agentes con el fin de explicar las categorías de percepción y apreciación (disposiciones) que estructuran su acción desde el interior" 40 . En términos de George Lakoff, las prenociones participarían de metáforas orientacionales que organizan el significado de elementos singulares por la relación que mantienen con los demás tales como la distinción arriba- abajo, dentro-fuera, delante-detrás, profundo-superficial, central-periférico ${ }^{41}$. El punto de partida-variable o no- de nuestra posición social, argumenta Bourdieu, es crucial para la formación del habitus:

Los condicionamientos asociados a una clase particulares de condiciones de existencia producen habitus, sistemas de disposiciones duraderas y transferibles, estructuras estructuradas predispuestas a funcionar como estructuras estructurantes, es decir, como principios generadores y organizadores de prácticas y de representaciones que pueden ser objetivamente adaptadas a su meta sin suponer el propósito consciente de ciertos fines ni el dominio expreso de las operaciones necesarias para alcanzarlos, objetivamente "reguladas" y "regulares" sin ser para nada el producto de la obedien-

36 "Bourdieu propone considerar que las divisiones sociales y los esquemas mentales son estructuralmente homólogos por estar genéticamente ligados: los segundos no son otra cosa que la encarnación de las primeras" BouRDIEU, Pierre, Waquant, Loïc, Una invitación a la sociología reflexiva. Ciudadela, Siglo XXI, 2008

37 Bourdieu, Pierre, "Espacio social y la génesis de las “clases"”, Espacios, 1985, núm. 2, 29-35pp. 32-33

38 Bourdieu, Pierre; Waquant, Loïc, op. cit., p.31

39 Bourdieu, Pierre, Chambordeon, Jean-Claude, Passeron, Jean-Claude, El oficio del sociólogo. México Siglo XXI, 2008, p. 32

40 Bourdieu, Pierre; Waquant, Loïc, op. cit., p. 35

41 Lakoff, George, Johnson, Mark, Metáforas de la vida cotidiana. Madrid, Cátedra, 1986, pp. 38-39. 
cia a determinadas reglas, y, por ello, colectivamente orquestadas sin ser el producto de la acción organizadora de un director de orquesta. ${ }^{42}$

Este sistema de disposiciones duraderas encarnadas en cada agente es crucial para pensar la efectividad masiva no orquestada de la masculinidad. Estas sirven de modelo experienciado y extrapolable a la situación política del individuo nacional: qué es valioso para lo masculino y qué lo degrada infesta las sociedades de prácticas orientadas a la conservación y aumento gradual de la virilidad. La homofobia y la transfobia, las expresiones coloquiales del lenguaje o la división de los espacios, los roles, los chistes o los targets publicitarios, participan de una lógica espontánea e inmanente que se sincroniza sin necesidad de directrices externas. Al poder potenciar o degradar la salud psico-somática y social de los agentes que participan de ella, la masculinidad tiene normas, defensas y patologías. En suma: condiciones de vivencia y supervivencia. ¿Qué es patológico para la forma de vida masculina? No solo aquello que la degrada, sino también todo aquello que la deja fuera de lugar o la margina. En un texto titulado Why guys drop bombs, Mark Juergensmeyer ensaya esta aproximación para el análisis de las relaciones entre masculinidad y terrorismo:

Nothing is more intimate than sexuality, and no greater humiliation can be experienced than failure over what one perceives to be one's sexual role. Such failures are often the bases of domestic violence; and when these failures are linked with the social roles of masculinity and femininity, they can lead to public violence. Terrorist acts, then, can be forms of symbolic empowerment for men whose traditional sexual roles - their very manhood-is perceived to be at stake ${ }^{43}$.

Si rastreamos las tensiones existentes entre los roles normativos de la masculinidad y las transformaciones sociales allí donde estas últimas pongan fuera de juego el rol naturalizado de la masculinidad protectora o evidencien su fracaso. Aunque se ha hecho hincapié en las variantes geográficas de la masculinidad, y la proliferación de supuestas "nuevas masculinidades" ${ }^{44}$, la diversidad no debe llevarnos a engaño. Como sostiene R.W. Connell en "Masculinity Politics"45 la organización pública y masculina de la política y la organización privada y femenina del trabajo doméstico y reproductor roza la universalidad. Por ello, la pregunta que debe llevarnos de vuelta a las demandas políticas de impenetrabilidad no es la universal ¿para qué sirve ser impenetrable?, sino, ¿en qué condiciones las poblaciones van a percibir como útil aquello que aumenta la sensación de impenetrabilidad? Si toda función requiere del escenario en que resulta funcional, ¿en qué condiciones el rol fetichizado de la masculinidad protectora puede retornar y dirigir triunfante los discursos públicos del juego político?

42 Bourdieu, Pierre, El sentido práctico. México, Siglo XXI, 2009

43 Jurgensmeyer, Mark., "Why Guys Drop Bombs", Terror in the mind of God: The global rise of religious violence, $3^{\mathrm{a}}$ ed., Berkeley, University of California Press, 2003, p. 198

44 Jackson, Peter, "The Cultural Politics of Masculinity: Towards a Social Geography", Transactions of the Institute of British Geographers, New Series, Vol. 16, No. 2 (1991),pp. 199-213

45 Connell. Raewyn, "Masculine Politics", Masculinities, California, University of California Press, 1995 


\section{Amigo dentro / enemigo fuera. Sobre identidades nacionales herméticas, fronteras con agujeros y flujos penetrantes}

Los muros son una pantalla en la que puede proyectarse la figura antropomorfa del otro como causa de los infortunios nacionales (...) En resumen, el intento de construir muros emerge - y es cómplice - de un discurso en el que la mano de obra extranjera, el multiculturalismo y le terrorismo se fusionan y pasan de consecuencia a causa de la laxitud de la contención de la nación y de las limitaciones cada vez mayores de la capacidad protectora del Estado. ${ }^{46}$

En su excepcional ensayo Estados amurallados, soberanía en declive, Wendy Brown argumenta que en momentos de incertidumbre social y económica el poder ficticio o teatral de la soberanía se desmorona y deja de cumplir su función tranquilizadora. La presencia de inmigrantes irregulares y la sombra del terrorismo internacional converge con la más que probada ineficacia de las barreras, desdibujando la línea imaginaria que separa, en cada territorio, el nosotros que estamos adentro de los Otros del afuera. "Al respecto, la soberanía se presenta como una fantasía (o una falacia) política extremadamente masculina de dominación. La penetración, la pluralización o la interrupción suponen su destrucción literal" 47 . Las identidades emergentes, lejos de ser dos, son una y su envés: identidades interdependientes que nacen a la vez en el momento en que se dibuja una frontera imaginaria entre una uniforme y otra informe: "«El extranjero» que aparece "conformado como una única criatura imaginaria a partir del material compuesto por inmigrantes, narcotraficantes y terroristas, y que representa la contaminación de las fronteras violadas y la desmasculinización de una permeable subjetividad ciudadana nacional e individual"48. La inmigración deja de ser capital humano explotable sin poder social, cultural o político alguno. Dejan de ser aquellos buscavidas que, no sin cierta ironía trágica, en ocasiones han trabajado de manera irregular en la construcción de los muros que los quieren dejar fuera ${ }^{49}$ para convertirse en un antígeno altamente peligroso con la capacidad de socavar los pilares históricos de las identidades nacionales. ¿Qué permite que este extranjero emerja como unidad a la que podemos oponernos de manera unitaria? Es aquí donde retorna la cuestión del isomorfismo entre el biopoder que amenaza y la bio-resistencia que resiste: de la unidad absoluta de la amenaza emana la unidad absoluta de lo amenazado: la unidad del extranjero como Otro absoluto solo se comprende en relación con la unidad metafísica del nosotros comunitario. Esta unidad sólo puede ser lograda si lo que comparte y monopoliza es su relación con un origen o un destino que, encarnado en un símbolo, bandera o significante vacío, hace de clave de bóveda para el cierre de la unidad comunitaria. Este esquema articula la fragilidad

46 Brown, W., Estados amurallados, soberanía en declive, Barcelona, Herder, 2015, pp. 170-171

47 Ibid. p. 174. La cursiva es nuestra.

48 Ibid. p.182. La cursiva es nuestra.

49 "La construcción de un muro que pretende detener la inmigración de mano de obra requerida por el capital crea numerosas ironías. Está la historia de la State Fence Company, una empresa que construyó una parte importante del muro fronterizo al sur de California, que en el transcurso de una década fue acusada tres veces por tener en nómina centenares de trabajadores sin documentación” Ibid. p. 161 
de un valor interno con la visibilidad de un protector externo, y se repite como fractal en cada una de las instancias en las que opera la inmunología masculina:

La vulnerabilidad y la penetrabilidad están casi universalmente codificadas como femeninas; la supremacía y los poderes de contención y protección soberanos, como masculinos (...) Este acoplamiento heterosexual de la nación feminizada y del Estado soberano masculinizado no deja de ser importante. Al carecer de la protección de un Estado soberano, la nación se encuentra vulnerable, susceptible de ser violada y desesperada. El amurallamiento restaura una imago del soberano y de su poder protector..$^{50}$

Sobre la unidad metafísica del extranjero como portador de un poder patológico desproporcionado se articula con facilidad la simplicidad retórica y el antagonismo estratégico del discurso político populista. Como ha señalado Villacañas Berlanga: "Puesto que el populismo construye el pueblo como comunidad, lo construye como totalidad. Pero en la medida en que lo construye mediante una operación hegemónica atravesada por el conflicto tiene que hacerlo mediante la fractura del cuerpo político en amigos y enemigos" ${ }^{51}$. En efecto, la inmunología política masculina cabalga la dimensión retórica populista para trazar una línea entre amigos y enemigos que codifica lo penetrante como amenaza, la frontera masculina como seguridad y la interioridad como comunidad idealmente virginal y de facto degradada. Por supuesto, este no sería sino el esquema teórico (el tipo ideal) que encada caso podría venir hibridado a elementos de discriminación racial, cultural o económica: nuestro objetivo no es reducir todas las singularidades al esquema de la fobia a la penetración ${ }^{52}$, sino ofrecer su recorte teórico para que este pueda ser identificado en el interior de fenómenos políticos que, aparentemente, solo compartirían entre sí el haber sido calificados como "populismos de derechas".

Por último, y en contraposición a los teóricos del populismo que han identificado en el discurso el momento ontológico de lo político ${ }^{53}$, la comprensión inmunológica que aquí hemos tratado de perfilar distingue una estructura dual: por un lado, los mecanismos de identificación de lo patológico, momento discursivo en el que conviven los todos los sujetos de enunciación política incluyendo movimientos sociales, partidos políticos y medios de comunicación, y por otro lado, los mecanismos de defensa y reacción vinculados, en primera instancia, a la memoria inmunológica de las poblaciones (todo el conjunto de asociaciones que permite el reconocimiento y la reacción ante amenazas). A este segundo conjunto de elementos - que deben acompañar y secundar necesariamente a los mecanismos inmunológicos de identificación - pertenecen tanto los dispositivos institucionales oficiales (ejército, policía, cuerpos

50 Brown, W., Estados amurallados, soberanía en declive, op. cit., p. 191

51 Villacañas Berlanga, J.L., Populismo. La Huerta Grande, Madrid, 2015

52 En ningún caso nuestro argumento sostiene que la fobia a la penetración sea la razón suficiente que subyace tras las reacciones políticas contra la inmigración. De facto, esta requiere de indicadores de procedencia extranjera como el color de piel, la lengua, el estatus socioeconómico o la religión que introducen factores inmunológico-políticos como la xenofobia, la islamofobia o la aporofobia. Lo fundamental de la fobia a la penetración es que permite el rechazo de lo extraño sin tener que definirlo, poniendo el énfasis en el valor y la fragilidad de un interior corrompible por la entrada penetrante de lo extraño.

53 Nos referimos en diagonal a la comprensión del populismo esbozada por Ernesto Laclau y Chantall Mouffe en Hegemonía y estrategia socialista (1895), y desarrollada hasta su culminación por Laclau en La razón populista (2005). 
de seguridad, sus tecnologías, infraestructuras, instrumentos) como aquellos elementos que, sin formar parte de los dispositivos inmunológico políticos oficiales, pueden hacer labores de ataque, defensa y/o neutralización política (por vía armada o pacífica) en caso de que los primeros fracasen en el cumplimiento de sus funciones. Esto es: aquellas prenociones, esquemas mentales, aptitudes prácticas y latencias registradas en la memoria política (nacional, regional, local y/o individual) de las poblaciones. De aquí se siguen dos cosas: primero, que los llamados "momentos populistas" — en que la población civil organiza su propia defensa política - esté vinculado a momentos de crisis institucional y de representación. En segundo lugar, esto nos obliga a matizar la supuesta "contingencia radical" de lo político. Mientras la primera permite al discurso político altos niveles de contingencia y creatividad performativa para identificar lo patológico y unificar al sujeto-pueblo al que éste amenaza, la densidad histórica y localizada del habitus encarnado en las poblaciones determina la rigidez de geografías erosionadas por inercias habituales y elementos latentes - respuestas contenidas y olvidadas que no ocupan lugar en el presente - que los cambios en las inercias habituales pueden llegar a desenterrar y reactivar. Sobre estos terrenos accidentados, el discurso político solo puede aspirar a reactivar de manera parcial o total los mecanismos ya predispuestos a la reacción inmune en las dos direcciones que marca la constricción de lo antropológico por lo biológico: la conservación o la adaptación. Para lo primero, es conveniente que aquello que se desea conservar encuentre un eco en las estructuras de las luchas cotidianas y locales, es decir, que exista, y no que sea necesario imaginárselo; para lo segundo, es deseable que la adaptación sugerida sea factible técnica y políticamente. En palabras de Terry Eagleton, "Tiene que haber una forma de examinar el presente que muestre en su interior cierto futuro como potencialidad; de otro modo, sólo se hace a la gente desear infructuosamente" ${ }_{54}$.

\section{Conclusiones}

Ya no es estrictamente necesario definir qué penetra, basta con señalar desde cualquier posición el peligro que supone la penetración para la frágil unidad imaginaria (arcaica o venidera) de los equilibrios comunitarios. Esto nos permite identificar la fobia a la penetración en un amplio margen discursivo desconocido para la extrema derecha del siglo XX. Hoy ni la islamofobia, ni el antisemitismo, ni la xenofobia, ni el supremacismo, ni la transfobia, tampoco la aporofobia, nos permiten explicar el auge de la extrema derecha. Al mismo tiempo, cuando almacenamos los fenómenos en el cajón de los populismos de derechas decidimos conceptual y políticamente poner en cuarentena todo aquello que estos fenómenos pueden decir de nuestras sociedades: siendo el "populismo" irracional per se, nada de lo que ellos contengan debería hacernos reflexionar y actuar en contra de la racionalidad de nuestros códigos normativos.

También hemos argumentado que la masculinidad se expresa en la reactividad inmunológico-política de una población humana cuando i) codifica lo penetrante como amenaza enemiga (tiene miedo/fobia a la penetración), ii) fetichiza y sublima simbólicamente la masculinidad de las fronteras como fuente de seguridad y iii) proyecta hacia el interior una comunidad amiga sin fisuras (virginal) y de facto fisurada, decadente o degradada.

54 Eagleton, T., Why Marx was right, New Heaven, Yale University Press, 2011, p.68 
Concluimos tipificando tres características de la inmunología política masculina que pueden orientar al análisis sociológico y politológico de casos específicos:

I. Vigor y libertad / decadencia y seguridad. El péndulo de la inmunología política masculina: la reactividad de la inmunología política pendula entre periodos de prosperidad y seguridad económica, en los que aparece simbólicamente alineada con la libertad expansiva, y periodos de declive soberano y económico, en los que se repliega al interior de lógicas securitarias con la voluntad de no ser penetrado. De aquí que los mismos mecanismos inmunológicos puedan permanecer camuflados detrás de expresiones aparentemente contradictorias con la fobia a la penetración.

II. La inmunología política masculina como "trampa" oculta en el sentido común: dado que la inmunología política masculina ya dispone de los elementos transversales que los proyectos hegemónicos progresistas aspiran a producir, en la lucha por el sentido común esta partiría de una posición de ventaja al poder anclar con esquemas mentales, prenociones y elementos latentes generalizados y preexistentes. La lucha hegemónica que persiga anclar un programa político con el sentido común puede caer en la trampa de la masculinidad: la identificación, impugnación y destrucción de estos mecanismos inmunológicos es a la vez imprescindible para la producción de un tejido inmunológico político feminista en que imperen sus normas y se combatan sus patologías. Dicha implantación exige la confrontación inevitable con los elementos constituyentes de una inmunología masculina tradicionalmente acomodada en el sentido común.

III. La masculinidad como fuente de reacciones biopolíticas autoinmunes: la lógica inmunológica de la masculinidad tiene un alto potencial paranoide capaz de transformar un gran volumen de anomalías inocuas en amenazas. Interseccionando con factores racistas, esta lógica se ha hecho patente en todas las políticas "populistas" que han servido al rechazo y al maltrato social e institucional de poblaciones "refugiadas": poblaciones huidas de la guerra y la miseria recibidas y puestas en cuarentena bajo el argumento de un potencial patológico presupuesto e incuestionado. Encarnada en la experiencia subjetiva de las poblaciones de tradición política y cultural patriarcal, y abierta a expectativas múltiples de reafirmación (sexual, militar, económica), la inmunología política masculina puede pensarse como una disposición de defensa bio-política que aumenta su reactividad en momentos en que el estrés social coincide con la omnipresencia de elementos extranjeros en el interior de un territorio nacional, lo que favorecería que lo yuxtapuesto (poblaciones migrantes en momentos de estrés económico, político y social) sea percibido bajo el signo de la causa. En las sociedades contemporáneas, constituidas por constantes flujos de personas y mercancías extrañas, la masculinidad puede ser considerada como la principal fuente de reacciones biopolíticas autoinmunes y de indefensiones ante amenazas reales, al codificar lo extraño como patológico y lo familiar como benefactor per se contra toda evidencia histórica.

\section{Bibliografía}

BOURDIEU, Pierre (1985): "Espacio social y la génesis de las “clases"”, Espacios, núm. 2, 29-35

BOURDIEU, Pierre (2009): El sentido práctico. México, Siglo XXI, BOURDIEU, Pierre (2015). La dominación masculina. Barcelona, Anagrama 
BOURDIEU, Pierre, CHAMBORDEON, Jean-Claude, PASSERON, Jean-Claude (2008) El oficio del sociólogo. México, Siglo XXI

BOURDIEU, Pierre, WAQUANT, Loïc, (2008): Una invitación a la sociología reflexiva, Ciudadela Siglo XXI

BROWN, Wendy (1988): Manhood and Politics: A Feminist Reading in Political Thought. New Jersey Rowman \& Littlefield

BROWN, Wendy (2015): Estados amurallados, soberanía en declive. Barcelona, Herder Editorial

CANGUILHEM, George (1971). Lo normal y lo patológico, Buenos Aires, Siglo XXI, Buenos Aires

CASTRO, Edgardo (2007): "Biopolítica y gubernamentalidad", TEMAS \& MATIZES. DOSSIÊ BIOPOLÍTICA, núm. 11.

CONNELL. Raewyn (1995): "Masculine Politics", Masculinities, California, University of California Press

DELEUZE, Gilles (2006): Diferencia y repetición. Buenos Aires, Amorrortu

EAGLETON, Terry (2011): Why Marx was right, New Heaven, Yale University Press

ESPOSITO, Roberto (2011): Bíos: Biopolítica y filosofía. Amorrortu, Buenos Aires.

FOUCAULT, Michel (2008): Seguridad, territorio, población: Curso del Collège de France (1977-1978), Akal, Madrid

FOUCAULT, Michel (2009): Historia de la sexualidad 1. La voluntad de saber. México, Siglo XXI

FOUCAULT, M., (2009) Nacimiento de la biopolítica: Curso del Collège de France (19781979), Madrid, Akal, 2009

FOUCAULT, Michel (2010): Hay que defender la sociedad. Sevilla, Akal, Sevilla.

FOUCAULT, Michel (2010): Las palabras y las cosas: Una arqueología de las ciencias humanas. Madrid, Siglo XXI,

FOUCAULT, Michel (2012): Vigilar y castigar: Nacimiento de la prisión. Madrid, Biblioteca Nueva

FOUCAULT, Michel (2014): Los anormales. Buenos Aires, Fondo de Cultura Económica.

IVARFLASTEN, Elisabeth (2008): "What Unites Right-Wing Populists?", Comparative Political Studies, 41, 3-23. doi: 10.1177/0010414006294168

JACKSON, Peter (1991): "The Cultural Politics of Masculinity: Towards a Social Geography", Transactions of the Institute of British Geographers, New Series, Vol. 16, No. 2, 1991

JUERGENSMEYER, Mark (2003): Terror in the mind of God: The global rise of religious violence, $3^{\text {a }}$ ed. University of California Press, Berkeley. doi: 10.2307/2658139

LAKOFF, George, JOHNSON, Mark (1986): Metáforas de la vida cotidiana. Madrid, Cátedra.

LERNER, Gerda (1990): La creación del patriarcado. Barcelona, Crítica

MACHEREY, Pierre (2011): De Canguilhem a Foucault. Buenos Aires, Amorrortu.

MILLET, Kate (2010): Política sexual, $1^{\text {a }}$ ed. Madrid, Cátedra,

MUHLE, Maria (2012) "Histoire(s) de la vie de Canguilhem á Foucault", en Epistemology and history, from Bachelard and Canguilhem to today's history of science, Berlín, Max Planck Institute for the History of Science, pp.182-195 
PODOBNIK, Boris, JUSUP, Marko, STANLEY, H. Eugene (2016): "Predicting the rise of right-wing populism in response to unbalanced immigration", arXiv

RYDGREN, Jens (2008): “Inmigration sceptics, xenophobes or racists?”, European Journal of Political Research, 47, 737-765. doi: 10.1111/j.1475-6765.2008.00784.x

SACCHI, Emiliano (2015): "Del munus común a la vida impersonal. Comunidad y biopolítica en R. Esposito", Revista Internacional de Comunicación y Desarrollo, 2015, 83-98.

SACCHI, Emiliano (2016): "Umbrales biológicos de la modernidad política en Michel Foucault", Daimon. Revista Internacional de Filosofía, 2016, núm. 68, 19-35. doi: http:// dx.doi.org/10.6018/daimon/202801

SALINAS, Adán (2015): La semántica biopolítica: Foucault y sus recepciones. Viñas del mar, CENALTES, 2015.

SULLFORT, Evelyne, El hecho femenino. Madrid, Argos Vergara, 1979.

TOOD W. Rees, (2010): Masculinites in Theory., Singapur, Wiley-Blackwell,. doi: 10.1002/9781444317312.ch1

VÁZQUEZ GARCÍA, Francisco (2015): “Canguilhem, Foucault y la ontología política del vitalismo", Logos, vol. 48: 165-187.

VILLACAÑAS BERLANGA, José Luis (2016): Latencia. La elaboración de la vivencia originaria Dianoia, Volumen LXI, 76, pp- 3-28

VILLACAÑAS BERLANGA, José Luis (2015): Populismo. Madrid, La Huerta Grande, 2015. 